\section{Differential Thermal Analysis of 'Elberta' and 'Flavorich' Peach Flower Buds to Predict Cold Hardiness in Georgia}

\author{
Jun Liu, Orville M. Lindstrom, and Dario J. Chavez ${ }^{1}$ \\ Department of Horticulture, University of Georgia, Georgia Experiment \\ Station, 1109 Experiment Street, Griffin, GA 30223
}

Additional index words. Prunus persica, artificial freezing test, DTA, cold resistance, $\mathrm{LT}_{50}$, LTE, supercooling

\begin{abstract}
Differential thermal analysis (DTA) has great potential as a quick and convenient cold hardiness determination method in plants. It measures freezing events inside of plant samples by detecting exotherm(s) produced when water changes from liquid to solid phase. DTA is highly sensitive to the experimental conditions and it has been reported to be ineffective among different fruit crops after acclimation of floral buds has occurred. The objective of this project was to establish DTA as a rapid and accurate method to predict peach floral bud cold hardiness from acclimation to deacclimation as compared with the traditional standard artificial freezing test. Floral buds of 'Elberta' and 'Flavorich' peach cultivars were subjected to DTA and artificial freezing tests throughout the winters of 2015-16 and 2016-17. Before deacclimation, two distinct exotherms, low-temperature exotherms (LTE) and high-temperature exotherms (HTE), were normally detected from floral bud DTA analyses. After deacclimation, DTA tests yielded only a few LTEs. However, incubation of floral buds at $-2{ }^{\circ} \mathrm{C}$ overnight before the cooling process of DTA tests yielded an increased number of LTEs for both seasons in comparison with samples directly run using DTA without incubation. Similarly, after deacclimation started, the temperature in which LTE occurred was correlated $(r=0.59-0.86)$ with $\mathrm{LT}_{50}$ (lethal temperature that damaged $50 \%$ of floral buds) when DTA samples were treated overnight at $-2{ }^{\circ} \mathrm{C}$. In our study, pretreatment of floral buds at $-2{ }^{\circ} \mathrm{C}$ overcame the inability of DTA to detect LTEs after deacclimation, which improved the ability and reliability of DTA to detect LTEs for more than $50 \%$ of the buds used per date per cultivar. DTA is a promising method to predict cold hardiness of peach plants.
\end{abstract}

Peach is an important fruit crop worldwide and is also the official fruit of the state of Georgia. In 2016, Georgia produced a total of 43,300 tons of fruit with a farm gate value of almost $\$ 48$ million (Wolfe and Stubbs, 2017). In Georgia, a major threat to peach production is damage produced by spring freezes. Winter weather in Georgia is usually mild, and does not normally cause low-temperature damage to peach plants. In spring, low temperature following warm periods causes most of the cold damage and yield losses when the most vulnerable tissue, floral buds, deacclimate (loss of cold hardiness). Peach plants deacclimate and become susceptible to freezing

Received for publication 22 Aug. 2018. Accepted for publication 28 Jan. 2019.

This project was funded by the Florida Specialty Crop Block Grant USDA/FDACS No. 021759.

This paper is a portion of a thesis by Jun Liu in fulfilling degree requirement for the University of Georgia. The authors thank Malgosia Florkowska and Oliff Weldon for their help, Pearson Farm for allowing us access to their commercial orchards, and the Georgia Peach Council and the Georgia Agricultural Commission for Peaches for their support.

${ }^{1}$ Corresponding author. E-mail: dchavez@uga.edu.
$50\left(\mathrm{LT}_{50}\right)$ (Bigras and Colombo, 2013; Levitt, 1980; Stergios and Howell, 1973).

Peach floral buds can avoid freezing damage through supercooling (Quamme, 1974). Supercooling occurs when water inside of the acclimated floral bud primordia stays liquid even when the temperature is below freezing. Cold-acclimated floral buds prevent ice nucleation within its primordia, which is a prerequisite of freezing. In this way, winter floral buds avoid water freezing and freezing damage altogether. When the temperature drops too fast, it triggers freezing of supercooled water, and leads to plant tissue lethal damage. Water in the floral bud scales and flower axis do not exhibit supercooling and usually do not result in damage when frozen (Ashworth and Wisniewski, 1991; Levitt, 1980).

DTA detects water freezing events in plant tissues by identifying exotherms caused by water freezing within a tissue. The exotherms develop by the released heat of fusion of water when it changes from liquid to solid phase. There are two distinct exotherm events in DTA analyses of an acclimated peach floral bud: 1) HTE occurs a few degrees Celsius below $0{ }^{\circ} \mathrm{C}$ and is associated with freezing of extracellular water and is nonlethal; and 2) LTE occurs at a lower temperature and is associated with freezing of deep supercooled water and lethal damage to plant tissues. In this way, DTA can be used as well to predict cold hardiness of plants (Quamme et al., 1972).

DTA is an efficient and convenient way of assessing cold hardiness as compared with the artificial freezing test (Burr et al., 1990). Estimation of cold hardiness using DTA is available in a few hours, in contrast to $24 \mathrm{~h}$ or a week when using the artificial freezing test. Nevertheless, DTA does not directly measure cold hardiness. It rather measures freezing temperature of supercooled water in tissues. The DTA profile can be affected by test conditions such as cooling rate, pretreatment temperature, and sampling methods (Biermann et al., 1979; Flinn and Ashworth, 1994; Quamme, 1986). In addition, DTA was found to be ineffective in detecting LTEs of blueberry floral buds when buds were attached to stems under a slow cooling rate mimicking natural freezing conditions (Flinn and Ashworth, 1994). Although strong correlations between LTE from DTA analyses and $\mathrm{LT}_{50}$ values from artificial freezing test of peach floral buds have been previously reported (Proebsting and Sakai, 1979; Quamme, 1974; Quamme et al., 1975), understanding the DTA analyses in peach and developing a more reliable DTA protocol that can be deployed for Georgia is an important priority of this research. The objective is to understand the effects of our climatic conditions that can be detrimental to peach production in specifically spring freezes. DTA will provide peach growers with up-to-date information of their peach varieties' cold hardiness. The objective of this study was to develop DTA as a useful and accurate method to predict cold hardiness of peach 
floral buds, by building correlations between DTA and artificial freezing test, and calibrating DTA against artificial freezing test.

\section{Materials and Methods}

Plant material. One-year-old twigs were randomly selected from 10-year-old 'Elberta' and 'Flavorich' peach plants grafted on 'Guardian' rootstocks growing in a commercial orchard at Fort Valley, GA, maintained following commercial guidelines (Horton et al., 2010). Samples were collected monthly from Nov. 2015 to Dec. 2015, biweekly from Oct. 2016 to Dec. 2016, and weekly from Jan. to Mar. of both 2016 and 2017. Approximately 60 stems per cultivar were collected at each collection date and transported to the University of Georgia Griffin Campus, Griffin, GA, in a cooler with ice. Samples were then kept in a refrigerator at $4{ }^{\circ} \mathrm{C}$ for no longer than a day before processing. Floral buds were excised for DTA tests. Stems were also trimmed into either stem sections of $5 \mathrm{~cm}$ or $20 \mathrm{~cm}$ with flower buds attached and were used for artificial freezing test as the reference test.

DTA tests. DTA was performed using thermoelectric modules (TEM) placed in a temperature-controlled freezing chamber (temperature and humidity chamber PR3FPH; Tabai ESPEC, Osaka, Japan). Each TEM contains 240 thermocouples to detect the release of heat produced from water freezing. Four floral buds of the same cultivar were placed per TEM and covered with an aluminum lid to keep buds in constant contact with the TEM and to reduce the noise produced by the constant air cycling inside the freezer. Twelve TEMs were used with buds of the same cultivar per DTA test per collection date (six TEMs were used from Oct. to Dec. 2015). In addition, two DTA tests were conducted with different pretreatment cooling schemes per collection date. The first DTA test, denoted hereafter as "regular DTA," used a cooling scheme that dropped temperature quickly to $-2{ }^{\circ} \mathrm{C}$, and then decreased temperature at a constant rate of $4{ }^{\circ} \mathrm{C} \cdot \mathrm{h}^{-1}$ until it reached $-27^{\circ} \mathrm{C}$. For the second DTA test, denoted hereafter as "pretreated DTA," samples were first incubated at $-2{ }^{\circ} \mathrm{C}$ overnight as a pretreatment, then were cooled at a rate of $-4{ }^{\circ} \mathrm{C} \cdot \mathrm{h}^{-1}$ until reaching $-27{ }^{\circ} \mathrm{C}$. The regular DTA was the standard method used throughout most of the experiments; however, the pretreated DTA test was created to improve exotherm identification in samples during deacclimation. The pretreated DTA started on 26 Jan. 2016, and continued after that date. Three temperature probes were used to record the temperature inside of the freezing chamber simultaneously when DTA tests were running. Temperatures when freezing events happened can therefore be traced. A Campbell Scientific (Logan, UT) data logger was connected to the TEMs and temperature probes to record the voltage signal and temperature every minute. The data were then plotted against time using SigmaPlot 13.0 software (San Jose, CA) to identify LTE and HTE.
Artificial freezing test. Artificial freezing tests were used as reference to detect tissue damage associated with freezing. Stems of both $5 \mathrm{~cm}$ and $20 \mathrm{~cm}$ with floral buds were wrapped in damp tissue paper at the basal end to prevent wilting. A temperature treatment gradient of 10 temperatures was used for this test, which were $4{ }^{\circ} \mathrm{C}$ (control), $-3{ }^{\circ} \mathrm{C},-6^{\circ} \mathrm{C}$, $-9{ }^{\circ} \mathrm{C},-12{ }^{\circ} \mathrm{C},-15{ }^{\circ} \mathrm{C},-18{ }^{\circ} \mathrm{C},-21{ }^{\circ} \mathrm{C}$, $-24{ }^{\circ} \mathrm{C}$, and $-27{ }^{\circ} \mathrm{C}$. At each temperature, four replicates per sample type $(5-\mathrm{cm}$ stem and $20-\mathrm{cm}$ stem) per cultivar were assigned and sealed in the same plastic bag corresponding to a freezing temperature treatment. The same temperature-controlled freezing chamber was used in the DTA test. Samples in bags were kept in the freezing chamber at a constant $-2{ }^{\circ} \mathrm{C}$ overnight. In the morning, the freezing chamber then was set to a decreasing rate of $-4{ }^{\circ} \mathrm{C} \cdot \mathrm{h}^{-1}$ starting at $-2{ }^{\circ} \mathrm{C}$ until reaching $-27{ }^{\circ} \mathrm{C}$. Bags corresponding to a temperature treatment were rapidly removed from the freezing chamber when the temperature inside the chamber reached their corresponding treatment temperature. Treatment temperatures were measured by three temperature probes placed in bags at different locations in the chamber. After the freezing treatments were done, samples were kept in a refrigerator for a week at $4{ }^{\circ} \mathrm{C}$ to recover and allow discoloration to develop. Floral buds were then evaluated for freezing damage by dissecting them longitudinally with a razor blade. Samples that showed discoloration and oxidation were scored as death. Samples with green and healthy structures were scored as alive. A total of eight floral buds were evaluated for each temperature treatment per cultivar. In a previous study (Liu, 2017), sampling types (floral buds attached to 5-cm stems vs. floral buds attached to 20$\mathrm{cm}$ stems) were shown to be not significantly different from each other and not to affect cold hardiness estimations. Therefore, critical bud temperature calculations were based on an average of the 16 replicates for the two sampling types of floral buds attached to stems (5-cm stems and 20-cm stems).

Data analysis. Temperatures corresponding to each exotherm per TEM were identified from the DTA profiles. The distribution of temperatures corresponding to each exotherm for each cultivar across all TEMs per date were evaluated using JMP Pro 13 software (SAS Institute Inc., Cary, NC). Usually, the distribution of exotherm temperatures fitted a Normal 2 Mixture distribution per date per cultivar. The first normal distribution corresponded to exotherms at higher temperatures and were considered HTEs. The second normal distribution corresponded to exotherms at lower temperatures and were considered LTEs (Figs. 1 and 2). Means of the Normal 2 Mixture distributions corresponding to HTE or LTE temperatures were used for further analyses. In a few cases when using the pretreated DTA, the distribution of exotherm temperatures fitted one normal distribution with all exotherms identified as LTEs. Examples of fitted distributions are shown in Fig. 2.
Critical bud temperatures $\left(\mathrm{LT}_{50}\right)$ were calculated from the results of visual evaluation from the artificial freezing tests. A nominal logistic model was fitted using the visual rating of buds to determine $\mathrm{LT}_{50}$ with JMP Pro 13. Pearson's correlations between critical bud temperature from artificial freezing test and LTE temperatures from DTA tests were performed. In addition, regression analyses with critical bud temperatures as the dependent variable and the LTEs from DTA as the independent variables were carried out with JMP Pro 13.

\section{Results}

Overall result and LTE detection. Exotherms were detected in floral buds of 'Elberta' and 'Flavorich' peach varieties (Fig. 1). Apart from occurring at a lower temperature, LTE peaks in DTA profiles tended to be sharper and narrower than HTE peaks. A connection error created issues with the DTA test of Oct. 2015 and data failed to be recorded. In the 2015-16 season, HTEs could always be detected. LTEs, on the other hand, were identified by regular DTA only before 23 Feb. 2016 (Tables 1 and 2). For both varieties in the 2015-16 season, the lowest LTE temperatures using the regular DTA were observed on 12 Jan. 2016, with LTE temperature of 'Elberta' being $-21.1^{\circ} \mathrm{C}$ and LTE of 'Flavorich' being $-16.2{ }^{\circ} \mathrm{C}$. As floral buds developed and progressed toward deacclimation, LTE peaks in DTA profiles grew taller and shifted to higher temperatures. After 23 Feb. 2016, exotherm peaks in the profile of regular DTA were wide and overlapping with each other (Fig. 1C and G), and LTEs were unable to be recognized due to loss of supercooling capability of the peach floral buds (Ashworth, 1984). DTA tests with $-2{ }^{\circ} \mathrm{C}$ pretreatment started on 26 Jan. 2016. LTEs of 'Elberta' were stable $\approx-18{ }^{\circ} \mathrm{C}$ from the start date of study to $23 \mathrm{Feb}$. 2016, suggesting full acclimation. For 'Flavorich' floral buds, LTE temperature from pretreated DTA showed more fluctuation (Fig. 3C). Afterward, LTE peaks from pretreated DTA tests shifted toward warmer temperatures and became fewer in number, but were still able to be distinguished by their narrow and sharper shapes within the DTA profiles toward the end of March (Fig. 1D and $\mathrm{H}$; Table 1).

For the 2016-17 season, the southeastern United States was characterized by an extremely warm winter. The chilling requirements (number of hours below $7.2{ }^{\circ} \mathrm{C}$ and above $0{ }^{\circ} \mathrm{C}$ that plants need to experience to break out of dormancy) of 'Elberta' and 'Flavorich' are 850 and 650 chilling hours (U.S. Department of Agriculture, 2017), respectively. In our experiment, at the last sampling date of 27 Mar. 2017, Fort Valley, GA, had accumulated only 633 chilling hours compared with 1100 to 1300 chilling hours accumulated on average (Griffin Campus, University of Georgia, 2017). The lack of chill in the 2016-17 season resulted in failure of dormancy break of 'Elberta' floral buds and a slow and nonuniform budbreak of 

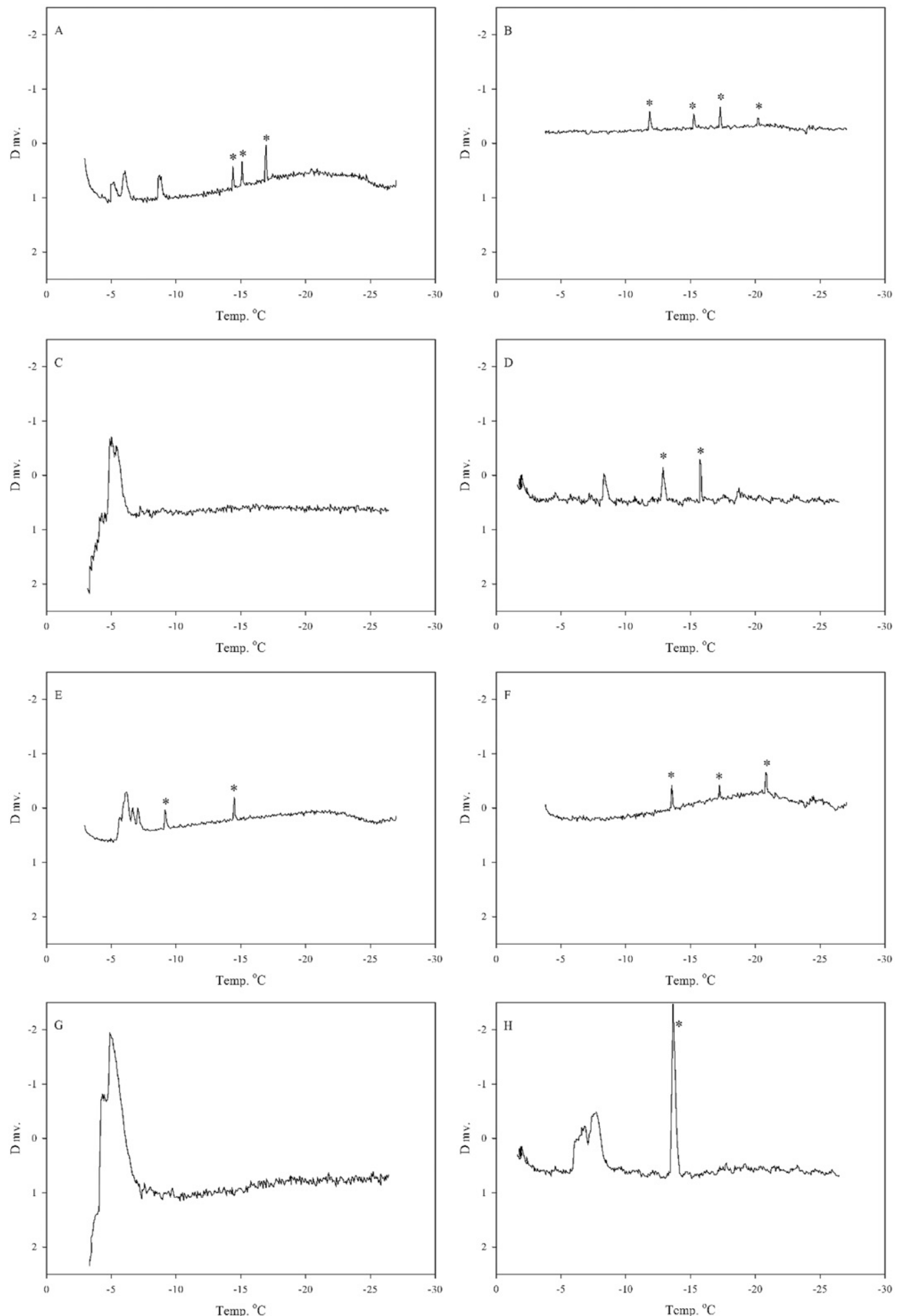

Fig. 1. Examples of differential thermal analyses (DTA) profiles of one thermoelectric module (TEM) during DTA tests. High-temperature exotherms (HTEs) and low-temperature exotherms (LTEs) can be distinguished by their shapes and locations. HTEs were observed at higher temperature (closer to positive values in the x-axis), and were wider than the LTEs. DTA profiles changed when tests were performed with different cultivars, bud stages, and DTA cooling schemes (with or without pretreatment). Acclimated floral buds of 'Elberta' (A, B) and 'Flavorich' (E, F) were collected on 26 Jan. 2016, and tested with both "regular DTA" (A, E) and with "pretreatment DTA" (B, F) for each cultivar, respectively. Deacclimated floral buds of 'Elberta' (C, D) and 'Flavorich' (G, H) were collected on 7 Mar. 2016, and similarly were subjected to both "regular DTA" (C, G) and DTA with "pretreatment" (D, H) for each cultivar, respectively. Symbol * denoted LTE peaks in the DTA profiles. Dmv $=$ differential millivolts.

'Flavorich' floral buds. Until the end of this study (end of March), only a few floral buds of 'Elberta' had broken in the orchard. The difference of responses to the natural accu- mulation of chill for the 2016-17 season for 'Elberta' and 'Flavorich' floral buds were also reflected in their DTA profiles (Fig. 3B and D).
No LTEs were detected for any DTA test at the beginning of the test periods of the 2016-17 season, except for regular DTA on 10 Oct. 2016 (Tables 1 and 2). After 11 Dec. 
2016, LTEs could be observed in all DTA tests, except for regular DTA on 9 Jan. 2017. For 'Elberta' floral buds, the lowest LTE estimated by regular DTA and pretreated DTA was $-18.7{ }^{\circ} \mathrm{C}$ on 6 Feb. 2017 and $-20.1{ }^{\circ} \mathrm{C}$ on 15 Jan. 2017, respectively (Fig. 3B; Table 1). Afterward, both pretreated DTA and regular DTA were able to detect LTEs until early spring (Fig. 3B; Table 1). LTEs of 'Elberta' floral buds obtained by both regular DTA and pretreated DTA did not reflect a clear acclimation and deaccli-
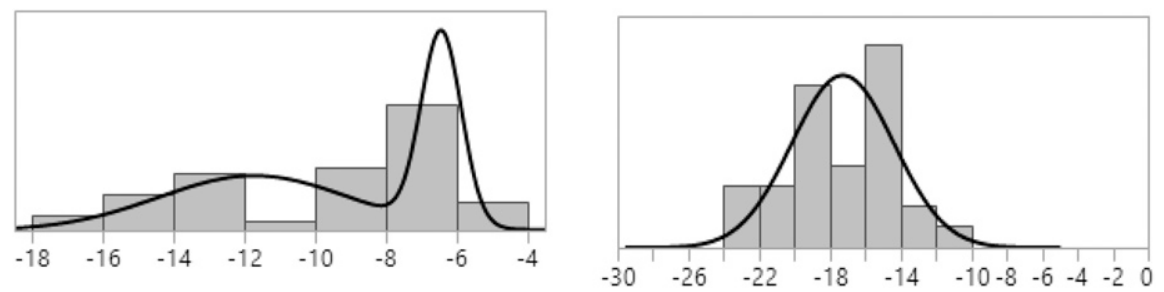

Fig. 2. Examples of temperature distribution of exotherm fitted by JMP Pro13. Samples were collected on 26 Jan. 2016. Forty-eight 'Flavorich' floral buds were tested for each test. Left: Normal 2 Mixture distribution of exotherms detected by regular DTA. Right: Normal distribution of exotherms detected by pretreated DTA. mation pattern (Fig. 3B). Even on the last sampling date, LTEs of 'Elberta' floral buds were $-16.8^{\circ} \mathrm{C}$ and $-17.2^{\circ} \mathrm{C}$ for regular DTA and pretreated DTA, which were close to the lowest LTE temperature (Table 1). For 'Flavorich', the acclimation process was not captured by the DTA tests either, because DTA data were only available from 11 Dec. 2017 (Fig. 3D). LTEs measured by regular DTA test for 'Flavorich' were $-17.0^{\circ} \mathrm{C}$ on 11 Dec. 2016, which is a large drop from $-9.2^{\circ} \mathrm{C}$ of the last available data on 10 Oct. 2016

.

(Table 2). LTE temperatures for regular DTA of 'Flavorich' floral buds were $\approx-17^{\circ} \mathrm{C}$ from 11 Dec. 2016 to $20 \mathrm{Feb}$. 2017, then started to increase afterward and reached $-14.6^{\circ} \mathrm{C}$ at the last sampling date on 27 Mar. 2017 (Fig. 3D; Table 2). LTE of regular DTA was always lower when compared with LTEs obtained during the 2015-16 season tests corresponding to the same period of analysis uring the 2016-17 season. Pretreated DTA obtained the lowest LTE temperatures of $21.6^{\circ} \mathrm{C}$ on 11 Dec. 2016 for 'Flavorich' oral buds. LTE temperature then increased ly until reaching $-14.1{ }^{\circ} \mathrm{C}$ on the last pling date. Similarly, LTEs of 'Flavorpretreated DTA in the season of 2015had more variation and fluctuation and higher temperature LTEs than the 17 test of the same period (for example, rich' LTE pretreated of $-7.7^{\circ} \mathrm{C}$ on 9 Mar. and $-10.2^{\circ} \mathrm{C}$ on 15 Mar. 2016 vs. treated of $-16.0{ }^{\circ} \mathrm{C}$ on 6 Mar. 2017

$4.4^{\circ} \mathrm{C}$ on 13 Mar. 2017) (Table 2).
number of LTE peaks detected for

Table 1. $\mathrm{LT}_{50}$ (lethal temperature that damaged $50 \%$ of floral buds) for floral buds attached to stems $(5 \mathrm{~cm}$ and $20 \mathrm{~cm}$ ), and low-temperature exotherms (LTEs) of regular and pretreated differential thermal analyses (DTAs) for 'Elberta' peach cultivar floral buds for winter seasons of 2015-16 and $2016-17$.

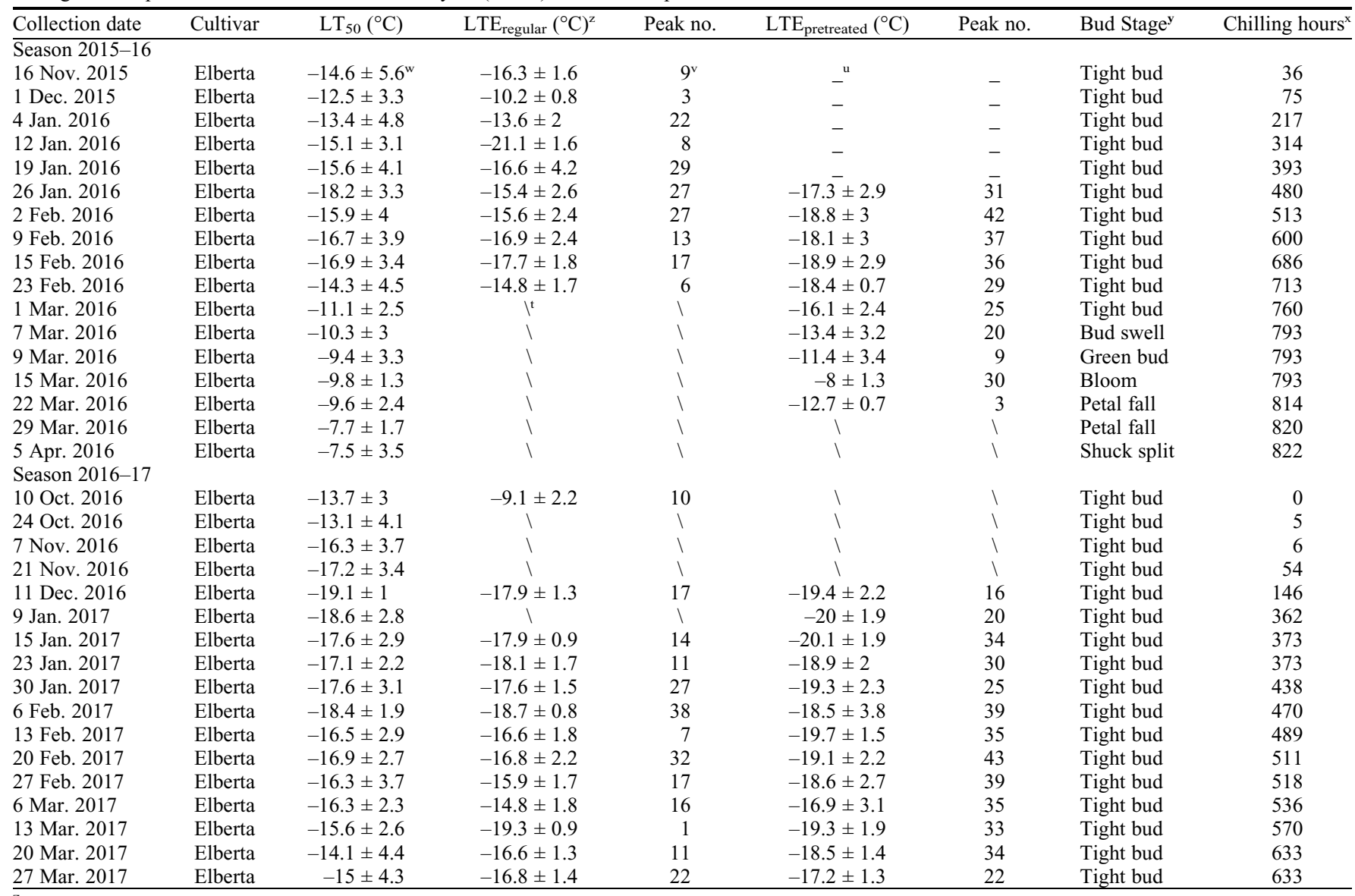

${ }^{\mathrm{z}} \mathrm{LTE}$ from regular DTA (no pretreatment) was denoted as LTE $\mathrm{L}_{\text {regular, }}$ and LTE from pretreated DTA was denoted as LTE $\mathrm{Lretreated}_{\text {. }}$

${ }^{\mathrm{y}}$ Most prominent floral bud development stage per date across samples (Horton and Johnson, 2005).

${ }^{\mathrm{x}}$ Chill hour accumulation in Fort Valley, GA, at each collection date based on the chilling hours model (temperature $\leq 7.2{ }^{\circ} \mathrm{C}$ ).

${ }^{\mathrm{w}}$ Mean values $\pm \mathrm{SD}$ for $\mathrm{LT}_{50}, \mathrm{LTE}_{\text {regular, }}$, and $\mathrm{LTE}_{\text {pretreated }}$ were reported.

${ }^{\mathrm{v}}$ A total of 48 floral buds were tested for DTA for each cultivar per date. The number of LTEs detected corresponded to these 48 buds, with the exception of the tests on 16 Nov. 2015 and 1 Dec. 2015, when 24 buds were tested.

${ }^{\mathrm{u}} \mathrm{S}$ Symbol_ represents dates in which DTA tests with pretreatment were not performed.

${ }^{\mathrm{t}} \mathrm{Symbol} \backslash$ represents dates in which DTA failed to detect LTE. 
Table 2. $\mathrm{LT}_{50}$ (lethal temperature that damaged $50 \%$ of floral buds) for floral buds attached to stems $(5 \mathrm{~cm}$ and $20 \mathrm{~cm}$ ), and low-temperature exotherms (LTEs) of regular and pretreated differential thermal analyses (DTAs) for 'Flavorich' peach cultivar floral buds for winter seasons of 2015-16 and 2016-17.

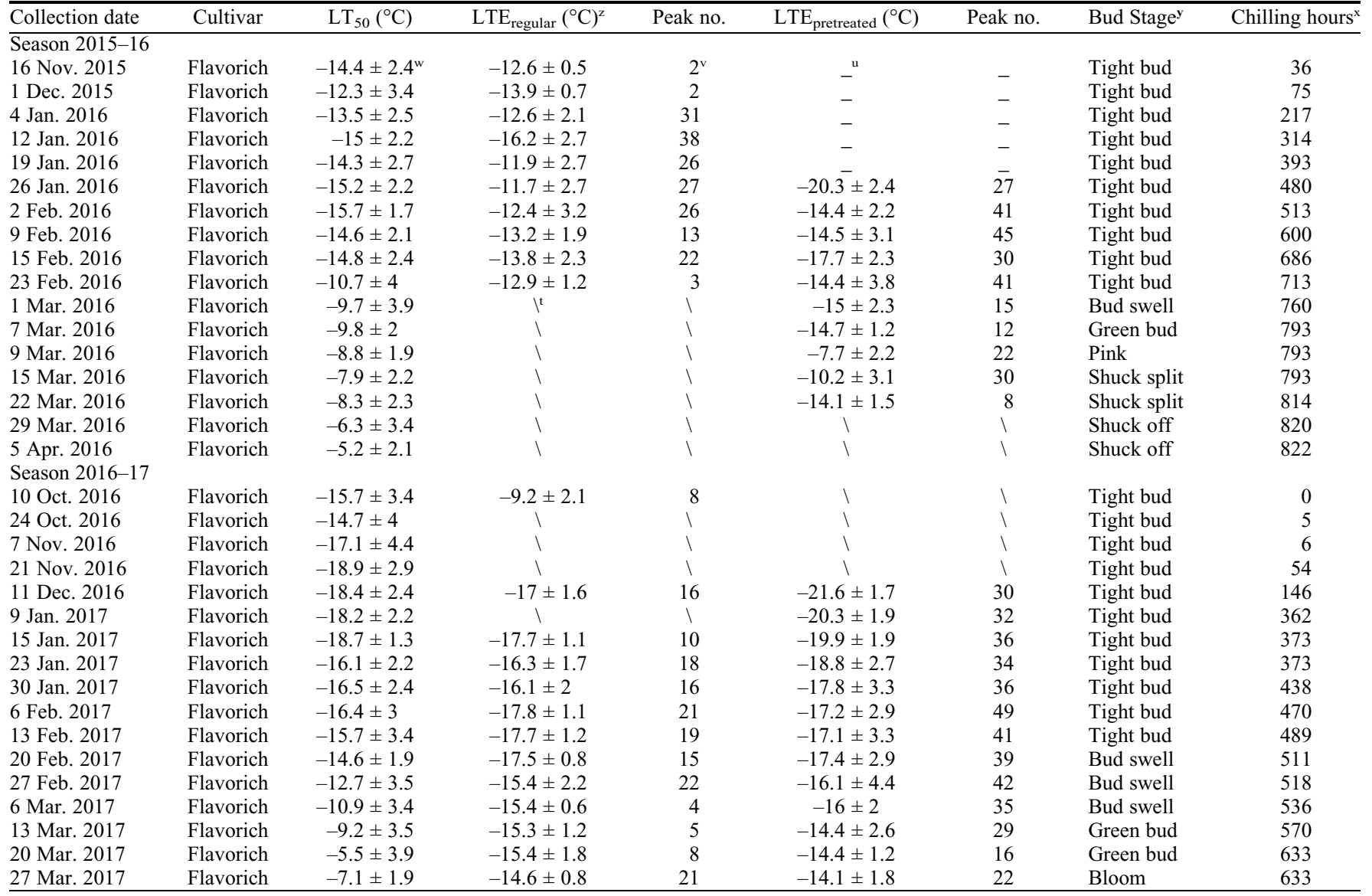

${ }^{\mathrm{z}} \mathrm{LTE}$ from regular DTA (no pretreatment) was denoted as LTE $\mathrm{L}_{\text {regular, }}$ and LTE from pretreated DTA was denoted as LTE pretreated.

${ }^{\mathrm{y}}$ Most prominent floral bud development stage per date across samples (Horton and Johnson, 2005).

${ }^{\mathrm{x}}$ Chill hour accumulation in Fort Valley, GA, at each collection date based on the chilling hours model (temperature $\leq 7.2{ }^{\circ} \mathrm{C}$ ).

${ }^{\mathrm{w}}$ Mean values $\pm \mathrm{SD}$ for $\mathrm{LT}_{50}, \mathrm{LTE}_{\text {regular }}$, and $\mathrm{LTE}_{\text {pretreated }}$ were reported.

${ }^{\mathrm{v}} \mathrm{A}$ total of 48 floral buds were tested for DTA for each cultivar per date. The number of LTEs detected corresponded to these 48 buds, with the exception of tests on 16 Nov. 2015 and 1 Dec. 2015, when 24 buds were tested.

${ }^{\text {uSymbol }}$ _represents dates in which DTA tests with pretreatment were not performed.

${ }^{\mathrm{t}} \mathrm{Symbol} \backslash$ represents dates in which DTA failed to detect LTE.

number of LTE peaks identified by using the pretreated DTA were usually more than regular DTA, especially after deacclimation.

Water content. Seasonal changes of water content of floral buds from both cultivars were recorded (Fig. 4). Floral bud water content remained stable during acclimation, and increased dramatically after floral bud deacclimation, which is clear for both cultivars in the 2015-16 season (Fig. 4A) and 'Flavorich' floral buds in the 2016-17 season (Fig. 4B). In the first season, deacclimation of both cultivars started on 23 Feb. 2016; in the second season, 'Flavorich' floral buds started deacclimating on 23 Jan. 2017. Floral buds of 'Elberta' did not deacclimate in the second season, and water content did not show the sharp increase as 'Flavorich' floral buds did (Fig. 4B). Water content of floral buds correlated well with $\mathrm{LT}_{50}$ after deacclimation across two winters for both cultivars, except for 'Elberta' in the 2016-17 test in which buds failed to deacclimate. The correlations were high, with $r=0.84$ for 'Elberta' in the 2015-16 season, $r=0.94$ and $r=0.95$ for 'Flavorich' in the 2015-16 and 2016-17 seasons, respectively. During deaccli- mation, water content also correlated well with the LTEs observed by the pretreated DTA, $r=$ 0.87 for 'Elberta' in the 2015-16 season, $r=$ 0.66 and 0.91 for 'Flavorich' in the 2015-16 and 2016-17 seasons, respectively.

Effect of pretreatment. In the 2015-16 test, LTEs from DTA tests with the $-2{ }^{\circ} \mathrm{C}$ pretreatment were reported at lower temperatures than LTEs measured by regular DTA for all the dates evaluated when data from both DTA tests were available (Fig. 3A and C). Deacclimation started on 23 Feb. 2016 for both cultivars, according to the artificial freezing test, which coincided with a sharp decline of the number of LTE peaks being detected using regular DTA (Tables 1 and 2). Afterward, regular DTAs yielded only one or two HTE peak(s) of approximately $-5{ }^{\circ} \mathrm{C}$ (Fig. 1C and G). Pretreated DTA tests, on the other hand, still had distinct peaks at lower temperatures (Fig. 1D and H).

LTE temperature of regular DTA and pretreated DTA were close in the 2016-17 test (Fig. 3B and D). LTE temperatures of 'Elberta' using the regular DTA were generally higher than those of the pretreated DTA except in two dates (within $0.3{ }^{\circ} \mathrm{C}$ of difference) (Fig. 3B). The results were consistent with the test of the 2015-16 season, when LTE temperature from pretreated DTA tended to be lower as well for 'Elberta' (Fig. 3A). LTE temperatures of 'Flavorich' floral buds for the two DTA tests in the 2016-17 season did not show a clear pattern (Fig. 3D).

A closer examination was made on data collected after deacclimation. Acclimation and deacclimation dates of floral buds were defined by the artificial freezing test results. After deacclimation, pretreated DTAs were not only able to detect more LTE peaks. In the 2015-16 season, deacclimation of peach floral buds initiated on 23 Feb. 2016 for both varieties. During the 2016-17 season, however, the artificial freezing test did not show clear deacclimation process as 'Elberta' floral buds did not progress beyond bud swell, which is the first growth stage of peach after buds break dormancy. Floral buds of 'Flavorich', on the other hands, started deacclimation $\approx 23$ Jan. 2017.

Correlations between LTE and $\mathrm{LT}_{50}$ were also examined to evaluate the credibility of 
A

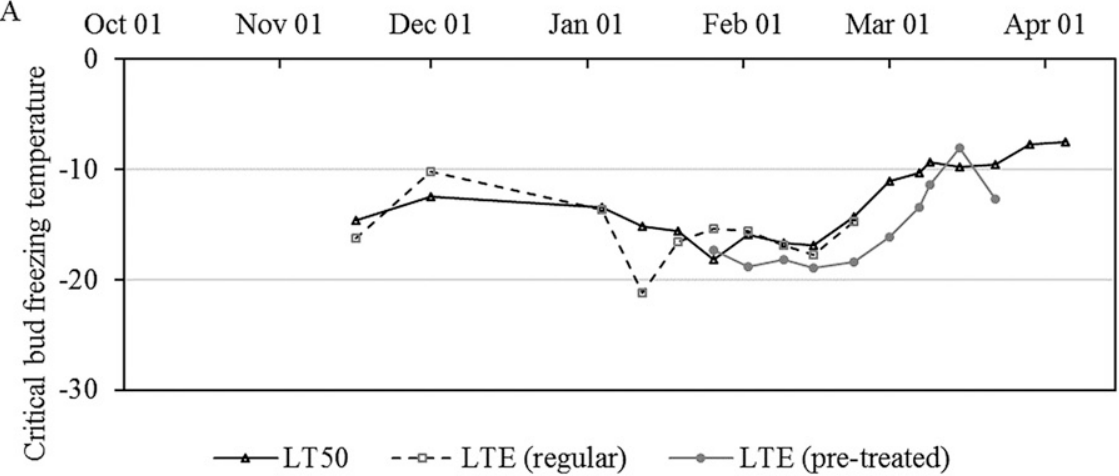

$\mathrm{B}$

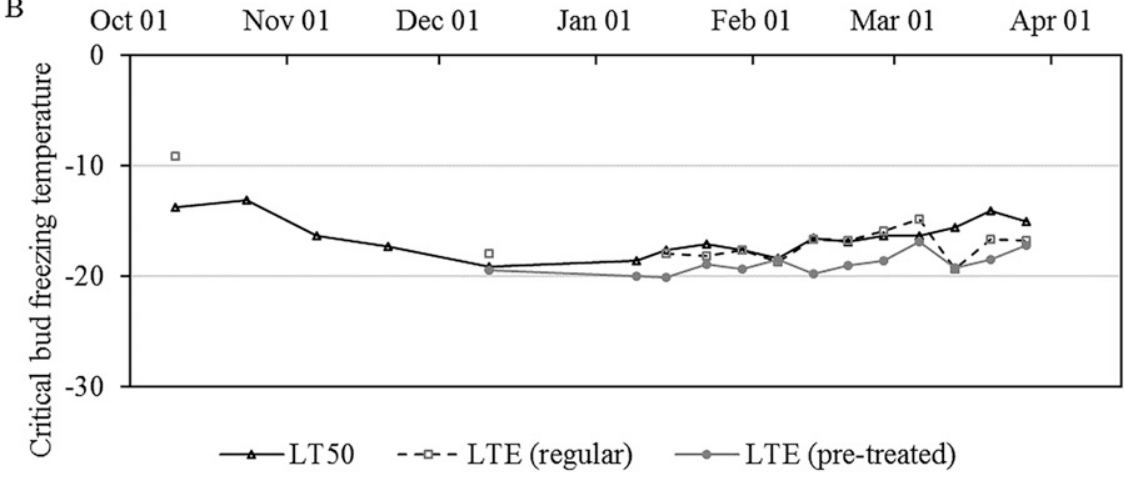

$\mathrm{C}$

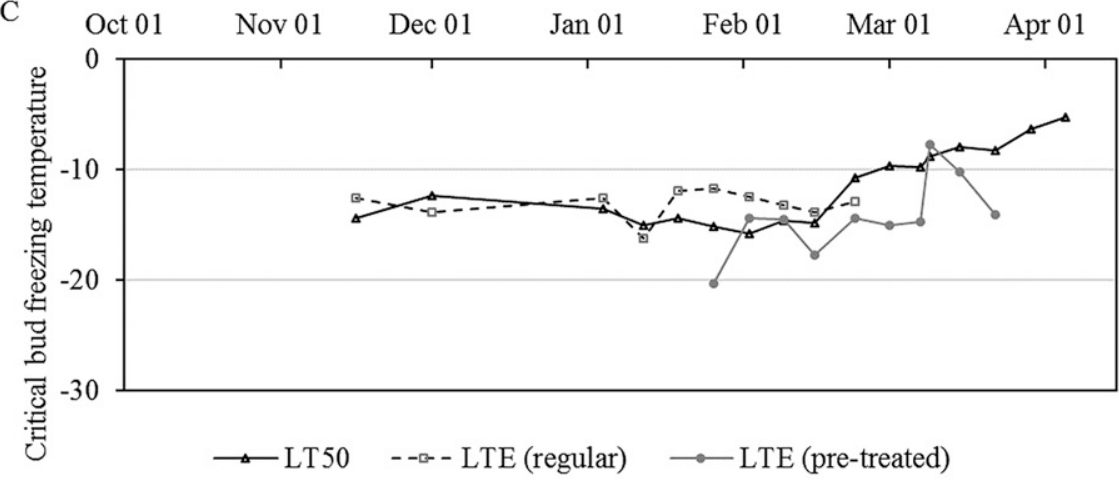

$\mathrm{D}$

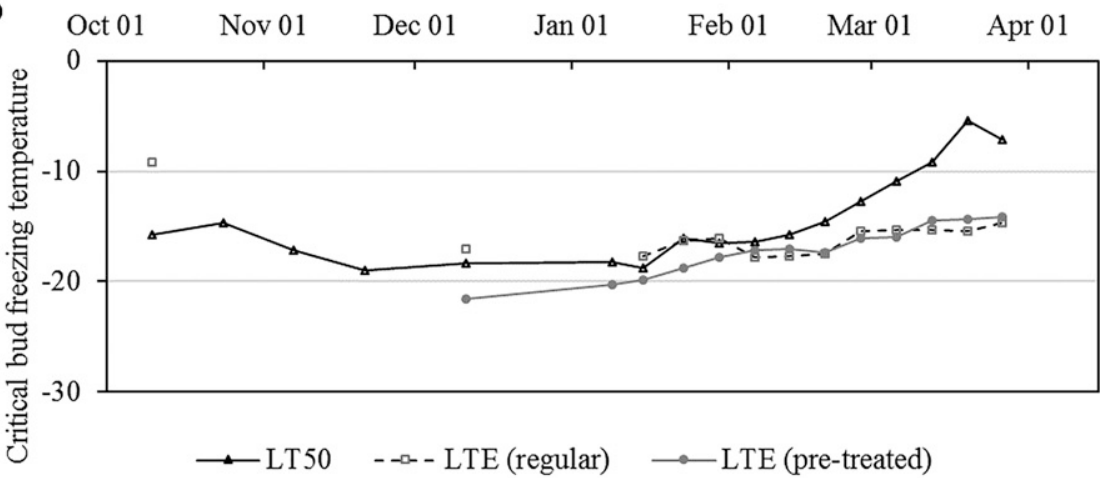

Fig. 3. Variation of critical bud temperature $\left(\mathrm{LT}_{50}\right)$ and temperatures of LTE from both DTA tests through time. Artificial freezing test and DTA were performed on 'Elberta' $(\mathbf{A}, \mathbf{B})$ and 'Flavorich' $(\mathbf{C}, \mathbf{D})$ through the winter season of 2015-16 (A, C) and winter season of 2016-17 (B, D). Temperatures of LTEs from regular DTA were noted as "LTE $E_{\text {regular" }}$ and temperature of LTEs from pretreated DTA were noted as "LTE

using the DTA test to predict the critical bud temperature of peaches. Overall across years, for 'Elberta', LTE temperatures from both DTA tests were correlated with $\mathrm{LT}_{50}$, with $r=0.59$ for regular DTA and $r=0.86$ for pretreated DTA. As for 'Flavorich' floral buds, LTE temperatures correlated with $\mathrm{LT}_{50}$ only if samples were treated with $-2{ }^{\circ} \mathrm{C}$ overnight, with a correlation coefficient of 0.77 . Similarly, linear regressions were tested to compare the reliability of regular DTA and pretreated DTA to predict cold hardiness. The regression equation to predict $\mathrm{LT}_{50}$ from $\mathrm{LTE}_{\text {regular }}$ for 'Elberta' floral buds was $\mathrm{LT}_{50}=\left(0.38 \times \mathrm{LTE}_{\text {regular }}\right)-$ $9.78\left[R^{2}=0.35\right]$, and $\mathrm{LT}_{50}=(0.39 \times$ $\left.\mathrm{LTE}_{\text {regular }}\right)-7.87\left[R^{2}=0.06\right]$ for 'Flavorich' floral buds. The regression equation to predict $\mathrm{LT}_{50}$ from $\mathrm{LTE}_{\text {pretreated }}$ for 'Elberta' floral buds was $\mathrm{LT}_{50}=\left(0.86 \times \mathrm{LTE}_{\text {pretreated }}\right)-$ $0.34\left[R^{2}=0.74\right]$, and $\mathrm{LT}_{50}=(0.96 \times$ $\left.\mathrm{LTE}_{\text {pretreated }}\right)+2.57\left[R^{2}=0.60\right]$ for 'Flavorich' floral buds. The coefficient of determination of regression from $\mathrm{LTE}_{\text {regular }}$ was lower than $\mathrm{LTE}_{\text {pretreated. }}$.

In a closer look within each season, 'Elberta' $\mathrm{LT}_{50}$ was correlated with pretreated DTA $(r=0.83)$ in 2015-16 season and with regular DTA $(r=0.61)$ in the 2016-17 season. 'Flavorich' $\mathrm{LT}_{50}$ was correlated with pretreated DTA $(r=0.67)$ in the $2015-16$ season, and with regular DTA $(r=0.80)$ and with pretreated DTA $(r=0.91)$ in the 2016-17 season. Similarly, linear regressions were tested. The regression equation to predict $\mathrm{LT}_{50}$ for 'Elberta' floral buds from $\mathrm{LTE}_{\text {pretreated }}$ was $\mathrm{LT}_{50}=\left(0.78 \times \mathrm{LTE}_{\text {pretreated }}\right)$ $1.23\left[R^{2}=0.70\right]$ in the 2015-16 season and from $\mathrm{LTE}_{\text {regular }}$ was $\mathrm{LT}_{50}=(0.38 \times$ $\left.\mathrm{LTE}_{\text {regular }}\right)-10.19\left[R^{2}=0.37\right]$ in the 201617 season. The regression equation to predict $\mathrm{LT}_{50}$ for 'Flavorich' floral buds from $\mathrm{LTE}_{\text {pretreated }}$ was $\mathrm{LT}_{50}=\left(0.60 \times \mathrm{LTE}_{\text {pretreated }}\right)-$ $2.91\left[R^{2}=0.45\right]$ in the 2015-16 season, and from $\mathrm{LTE}_{\text {regular }}$ was $\mathrm{LT}_{50}=(3.07 \times$ $\left.\mathrm{LTE}_{\text {regular }}\right)+36.72\left[R^{2}=0.64\right]$ and from $\mathrm{LTE}_{\text {pretreated }}$ was LT $\mathrm{LT}_{50}=\left(1.70 \times \mathrm{LTE}_{\text {pretreated }}\right)+$ $15.59\left[R^{2}=0.83\right]$ in the $2016-17$ season.

\section{Discussion}

In this study, we explored different methods to estimate/predict cold hardiness of peach in the southeast region of the United States. The artificial freezing test and the $\mathrm{LT}_{50}$ temperature have been long used to test and express freezing resistance of plants (Levitt, 1980). DTA is a method known by its objectivity and rapidity (Burr et al., 1990) and having great potential for cold hardiness predictability. However, the credibility of DTA to predict cold hardiness is still open to dispute (Flinn and Ashworth, 1994). DTA is highly sensitive to experimental conditions such as cooling rate temperature treatment, bud excision, and pretreatment temperatures (Andrews and Proebsting, 1987; Andrews et al., 1983; Biermann et al., 1979).

The cooling rate for DTA has been recommended to be close to freezing temperatures occurring in nature $\left(1\right.$ to $\left.2^{\circ} \mathrm{C} \cdot \mathrm{h}^{-1}\right)$ (Flinn and Ashworth, 1994). Proebsting and Sakai (1979) also suggested using a cooling rate "that will not affect the result." Yet, experimental conditions that resemble nature (low cooling rate of $2{ }^{\circ} \mathrm{C} \cdot \mathrm{h}^{-1}$ and floral buds attached to stem) failed to detect LTEs using DTA in the case of blueberry floral buds (Flinn and Ashworth, 1994). Levitt (1980) suggested a standardized cooling rate for artificial freezing test, which applies for DTA as well. In our study, we tested two cooling schemes. Regular DTA test started 


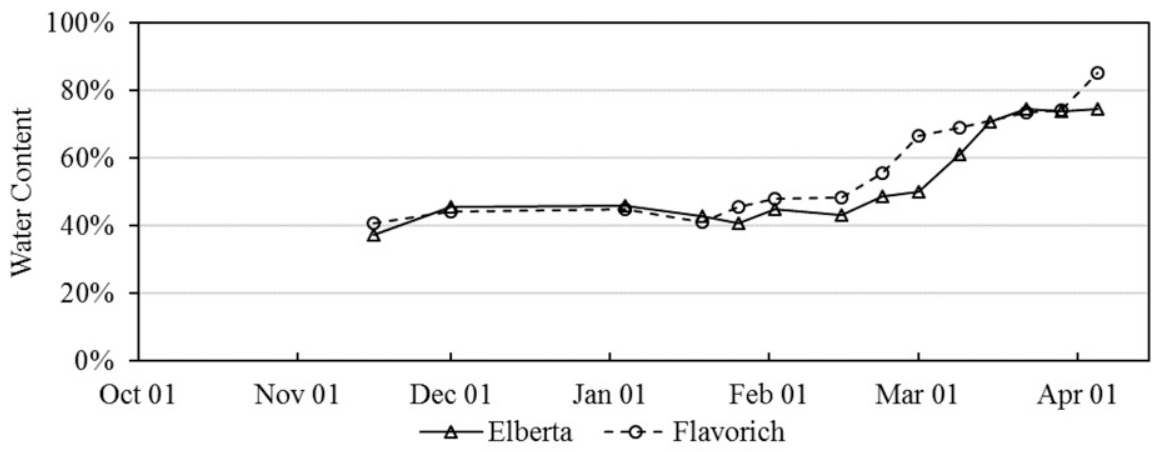

B

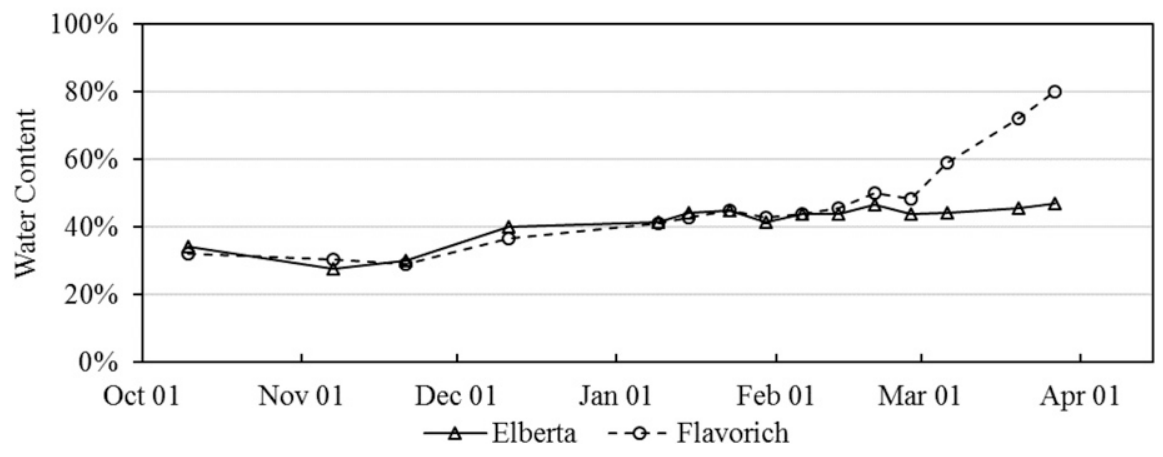

Fig. 4. Seasonal fluctuation of water content in floral buds of 'Elberta' and 'Flavorich' in the winter season of 2015-16 (A) and winter season of 2016-17 (B). Bud water content was expressed as percentage of floral bud fresh weight.

with a temperature of $-2{ }^{\circ} \mathrm{C}$ and then dropped air temperature to $-27^{\circ} \mathrm{C}$ with a cooling rate of $4{ }^{\circ} \mathrm{C} \cdot \mathrm{h}^{-1}$. The other DTA test, pretreated DTA, consisted of incubating the sample at $-2{ }^{\circ} \mathrm{C}$ overnight and then following the same cooling scheme as regular DTA. In our study, we observed that pretreated DTA was shown to perform better than regular DTA especially after floral bud deacclimation. It detected LTEs when regular DTA failed in the 201516 season, and captured more LTE peaks than regular DTA in the 2016-17 season (Fig. 1; Tables 1 and 2). Pretreated DTAs were also shown to detect LTEs for more than $50 \%$ of the buds used per date per cultivar.

Low temperature at $-2{ }^{\circ} \mathrm{C}$ overnight allowed water to relocate from primordia cells to apoplastic spaces, bud scales, and axis, breaking continuity of the water within the bud, which serves as ice propagation path (Quamme 1983, 1986). Incubating samples at $-2{ }^{\circ} \mathrm{C}$ blocked ice nucleation outside of primordia and promoted supercooling without inducing additional low-temperature damage. Therefore, the pretreatment separated merging peaks in the DTA profile of deacclimated buds and facilitated detection of LTEs. Water relocation also reduced water content within bud primordia. Floral buds with low water content have lower chance to trigger ice nucleation, thus freeze at a lower temperature. In our study, we noted that LTEs of pretreated DTA tended to occur at a lower temperature than LTEs from regular DTA (Tables 1 and 2). Similar water movement was observed in peach floral buds after acclimation at $-10{ }^{\circ} \mathrm{C}$ for $10 \mathrm{~d}$ by
Quamme (1983). LTEs of those buds appeared at lower colder temperature than buds treated at $0{ }^{\circ} \mathrm{C}$ (Quamme, 1983). Also, it is important to mention that the number of LTEs detected in pretreated DTAs were higher than those detected with the regular DTA, which could have shifted the overall mean for a date and cultivar to lower temperatures (Tables 1 and 2).

The pattern of LTE temperatures of pretreated DTA were lower than that of regular DTA. This pattern clearly holds true for 'Elberta' for both years and for 'Flavorich' for season one, but not so for 'Flavorich' in the 2016-17 season (Fig. 3D). Xylem continuity between floral bud primordia and bud axis can play an important part in the supercooling capability of the buds, as discussed earlier. After deacclimation, peach floral bud loses its ability of supercooling as xylem vessel elements developed and give free access to ice to enter bud primordia (Ashworth, 1982, 1984). Presumably, after xylem continuity is established, lowtemperature pretreatment would no longer facilitate supercooling. The winter of 201617 was unseasonably warm and offered insufficient chilling hours for peach plants. Floral buds of 'Flavorich' deacclimated quite early in the last season (23 Jan. 2017), and had prolonged nonuniform bloom. Floral buds might have established the xylem continuity early on without advanced morphological progress. Thus, incubating floral buds at $-2{ }^{\circ} \mathrm{C}$ overnight did not affect the internal water behavior in 'Flavorich' floral buds as we expected. On the other hand, 'Elberta' floral buds did not deacclimate or break. However, if this hypothesis stood true, floral buds of 'Flavorich' would lose supercooling ability and LTE would not occur at low temperature as we observed. It is worth noting that HTE was generally missing in the pretreated DTA test for 'Flavorich' (data not shown). Therefore, this hypothesis remains to be tested.

The effect in LTE estimation after treating floral buds with low temperature overnight might alternatively be explained by the loss of moisture. Kovacs et al. (2002) performed DTA test on grape floral buds to study the effect of moisture loss during sample processing. Interestingly, 'Vignoles' and 'Norton' grape floral buds lost $\approx 10.5 \%$ and $6.9 \%$ of their water after being excised from the stem and left at room temperature for $5 \mathrm{~min}$. A $6.5 \%$ and $4.3 \%$ moisture loss of 'Vignoles' and 'Norton' buds significantly decreased their LTE temperature $(P<0.001)$. In our study, floral buds of both cultivars normally lost $10 \%$ of the fresh weight of buds after a regular DTA test, whereas after a DTA test with pretreatment, weight loss was usually $\approx 30 \%$ of the fresh weight of buds (data not shown).

The correlations between $\mathrm{LT}_{50}$ and LTE temperatures from pretreated DTA were higher than correlations between $\mathrm{LT}_{50}$ with LTEs from regular DTA after deacclimation. It is important to mention that due to seasonal differences for 2015-16 and 2016-17, the correlations between $\mathrm{LT}_{50}$ and regular and/or pretreated DTA values did not hold true. This is believed to be the result of the different deacclimation processes when comparing 'Elberta' vs. 'Flavorich', especially in the 2016-17 season, where 'Elberta' never deacclimated because of the lack of accumulated chill required to break dormancy.

Correlations between floral bud LTE measured by DTA and floral bud $\mathrm{LT}_{50}$ have been previously reported in various plant species. In Prunus spp., Quamme (1974) tested 'Elberta' and 'Siberian C' peach floral buds from November to late March and found that LTE and $\mathrm{LT}_{50}$ temperatures were similar, with less than $2.5^{\circ} \mathrm{C}$ of difference. He further tested 10 peach varieties in winter and found good correlations between $\mathrm{LT}_{50}$ and LTE, $r=$ 0.880 (Quamme et al., 1975). In other Prunus spp., floral bud LTE temperatures were also reported to be close to $\mathrm{LT}_{50}$ (Andrews and Proebsting, 1987; Quamme, 1974). For blueberry floral buds, correlations of LTEs to $\mathrm{LT}_{50}$ were high during acclimation and midwinter with $r=0.85$ (Biermann et al., 1979). Floral buds were subjected to DTA test without pretreatment, which suggested that regular DTA might be suited for cold hardiness estimation of acclimated floral buds during midwinter. In our study, however, data collection during acclimation was not extensive. In the 2015-16 season, floral buds were acclimated in four of all our collection dates. In the 2016-17 season, 'Flavorich' deacclimated early, leaving us with three dates of data available from DTA test before deacclimation. Future studies are needed to accumulate more data during acclimation. 
During the acclimation process of the 2016-17 season, both DTA tests failed to detect exotherms. During 2016 and early 2017, the southeastern United States and the State of Georgia were suffering from a drought, which might have contributed to the failure of DTA tests to detect exotherms. Water content of floral buds at the end of 2016 was much lower than the water content at end of 2015 (Fig. 4), which supported this assumption. The heat of fusion released from water during the phase transition could have been too small to be sensed by a thermocouple when the bud water content was too low. Thus, exotherm events failed to be captured by DTA analyses. In this context, Biermann et al. (1979) tested floral buds from a hardy blueberry hybrid during midwinter, and he found that coldadapted floral buds with low tissue moisture content yielded no DTA exotherms.

In summary, we explored the potential of DTA to accurately predict cold hardiness. Our results showed that the pretreated DTA was able to overcome the inefficiency of detecting LTEs after deacclimation, offering high correlations when compared with the standard artificial freezing test. Similarly, we observed that the predictability of cold hardiness using regular and/or pretreated DTA may be affected by unseasonable warm winters (a.k.a. reduced chill) due to possible changes of the deacclimation process of the varieties being evaluated (especially if those varieties lack the accumulated chill required to break dormancy).

Overall, DTA would allow growers to obtain cold hardiness information from samples collected in the field $1 \mathrm{~d}$ before the forecasted freeze event. This method would allow our program to predict possible damages produced by upcoming freeze events based on the cold hardiness information of different varieties. This will help growers to better allocate resources and decide their freeze protection strategies, for example, turning on irrigation or wind machines for the night to protect cold-susceptible cultivars. In the future, calibration and further refinement of our prediction models is needed for DTA to accurately predict cold hardiness of plants under natural conditions and different seasons. Also, more studies are required to analyze samples that have low water content.

\section{Literature Cited}

Andrews, P.K. and E.L. Proebsting, Jr. 1987. Effects of temperature on the deep supercooling characteristics of dormant and deacclimating sweet cherry flower buds. J. Amer. Soc. Hort. Sci. 112:334-340.

Andrews, P.K., E.L. Proebsting, Jr., and D.C. Gross. 1983. Differential thermal analysis and freezing injury of deacclimating peach and sweet cherry reproductive organs. J. Amer. Soc. Hort. Sci. 108:755-759.

Ashworth, E. and M. Wisniewski. 1991. Response of fruit tree tissues to freezing temperatures. HortScience 26:501-504.

Ashworth, E.N. 1982. Properties of peach flower buds which facilitate supercooling. Plant Physiol. 70:1475-1479.

Ashworth, E.N. 1984. Xylem development in Prunus flower buds and the relationship to deep supercooling. Plant Physiol. 74:862-865.

Biermann, J., C. Stushnoff, and M. Burke. 1979. Differential thermal analysis and freezing injury in cold hardy blueberry flower buds. J. Amer. Soc. Hort. Sci. 104:444-449.

Bigras, F.J. and S. Colombo. 2013. Conifer cold hardiness. Springer, Dordrecht, Netherlands.

Burr, K.E., R.W. Tinus, S.J. Wallner, and R.M. King. 1990. Comparison of three cold hardiness tests for conifer seedlings. Tree Physiol. 6:351-369.

Flinn, C.L. and E.N. Ashworth. 1994. Blueberry flower-bud hardiness is not estimated by differential thermal analysis. J. Amer. Soc. Hort. Sci. 119:295-298.

Griffin Campus, University of Georgia. 2017. Chilling Hours Calculator. The Georgia Automated Environmental Monitoring Network, Griffin. 18 July 2017. <http://weather.uga.edu/>.

Horton, D., P. Brannen, B. Bellinger, and D. Ritchie. 2010. Southeastern peach, nectarine and plum pest management and culture guide. Cooperative Extension Bulletin No. 1171. University of Georgia, Athens, GA.

Horton, D. and D.T. Johnson. 2005. Southeastern peach growers' handbook. University of Georgia, Cooperative Extension Service, Athens, GA.

Kovacs, L.G., G. Du, and P. Ding. 2002. Tissue moisture loss during sample preparation lowers exotherm temperatures in dormant grape buds. HortScience 37:701-704.

Levitt, J. 1980. Responses of plants to environmental stress, Volume 1: Chilling, freezing, and high temperature stresses. 2nd ed. Academic Press, New York, NY.

Liu, J. 2017. Revisiting cold hardiness of peach in Georgia. Univ. of Ga., Athens, MS Thesis.

Proebsting, E.L., Jr. and A. Sakai. 1979. Determining T50 of peach flower buds with exotherm analysis. HortScience 14:597-598.

Quamme, H. 1974. An exothermic process involved in the freezing injury to flower buds of several Prunus species. J. Amer. Soc. Hort. Sci. 99:315-318.

Quamme, H. 1983. Relationship of air temperature to water content and supercooling of overwintering peach flower buds. J. Amer. Soc. Hort. Sci. 108:697-701.

Quamme, H. 1986. Use of thermal analysis to measure freezing resistance of grape buds. Can. J. Plant Sci. 66:947-952.

Quamme, H., R. Layne, H. Jackson, and G. Spearman. 1975. An improved exotherm method for measuring cold hardiness of peach flower buds. HortScience 10:521-523.

Quamme, H., C. Stushnoff, and C. Weiser. 1972. The relationship of exotherms to cold injury in apple stem tissues. J. Amer. Soc. Hort. Sci. 97:608-613.

Stergios, B.G. and G.S. Howell. 1973. Evaluation of viability tests for cold stressed plants. J. Amer. Soc. Hort. Sci. 98:325-330.

U.S. Department of Agriculture, Risk Management Agency. 2017. 2017 Peach Variety Listing.

Wolfe, K. and K. Stubbs. 2017. 2016 Georgia Farm Gate Value Report. The Center for Agribusiness \& Economic Development, College of Agriculture \& Environmental Science, University of Georgia, Athens, GA. 